\title{
A geografia econômica no XI ENANPEGE (2015): diálogos possíveis
}

Géographie économique dans XI ENANPEGE (2015): dialogues possibles

La geografía económica en el XI ENANPEGE (2015): diálogos posibles

Economic geography in XI ENANPEGE (2015): possible dialogues

\section{Luana Guidoni}

\section{(2) OpenEdition}

\section{Journals}

\section{Edição electrónica}

URL: http://journals.openedition.org/espacoeconomia/6269

DOI: 10.4000/espacoeconomia.6269

ISSN: 2317-7837

\section{Editora}

Núcleo de Pesquisa Espaço \& Economia

\section{Refêrencia eletrónica}

Luana Guidoni, «A geografia econômica no XI ENANPEGE (2015): diálogos possíveis », Espaço e Economia [Online], 14 | 2019, posto online no dia 12 agosto 2019, consultado o 07 setembro 2019 URL : http://journals.openedition.org/espacoeconomia/6269 ; DOI : 10.4000/espacoeconomia.6269

Este documento foi criado de forma automática no dia 7 Setembro 2019

(C) NUPEE 


\title{
A geografia econômica no XI ENANPEGE (2015): diálogos possíveis
}

\author{
Géographie économique dans XI ENANPEGE (2015): dialogues possibles \\ La geografía económica en el XI ENANPEGE (2015): diálogos posibles \\ Economic geography in XI ENANPEGE (2015): possible dialogues
}

\section{Luana Guidoni}

\section{Introdução}

1 A geografia é uma ciência que possui diferentes subáreas, uma delas é a geografia econômica, que é oriunda da convergência entre a geografia e a economia. Seu principal papel é o de analisar o planeta terra em todos os aspectos que interferem na economia, como a influência que a cultura detém sobre o consumo, os circuitos econômicos, estudos sobre a flexibilização e a metropolização. É uma ciência que tem um aspecto espacial ou locacional.

2 A geografia econômica é importante para análise das questões presentes no mundo atual, auxiliando na procura de possíveis caminhos para sua superação. Além disso nos ajuda analisar a influência provocada sobre os sistemas globais. Dessa maneira, com o intuito de identificar as pesquisas que estão sendo produzidas na área da geografia econômica optamos por elaborar um estado da arte. Essa investigação nos permite analisar o conhecimento que vem sendo desenvolvido nas pesquisas científicas nas universidades públicas brasileiras nessa subárea do conhecimento.

e acordo com (FERREIRA 2002, p.258) esse tipo de pesquisa tem "caráter bibliográfico, elas parecem trazer em comum o desafio de mapear e de discutir uma certa produção acadêmica em diferentes campos do conhecimento, tentando responder que aspectos e dimensões vêm sendo destacados e privilegiados em diferentes épocas e lugares". Dessa forma ao ser efetuado esse levantamento, há a possibilidade de se verificar sobre o modo de como vem sendo produzido o conhecimento, que público é investigado.

Soares $(1987$, p. 9) relata a importância do estado da arte sobre determinado tema: 
Essa compreensão do estado de conhecimento sobre um tema, em determinado momento, é necessária no processo de evolução da ciência, afim de que se ordene periodicamente o conjunto de informações e resultados já obtidos, ordenação que permita indicação das possibilidades de integração de diferentes perspectivas, aparentemente autônomas, a identificação de duplicações ou contradições, e a determinação de lacunas e vieses.

O estado da arte exige reflexão e criticidade por parte do investigador, e se mostra necessário ao enfatizar as pesquisas já feitas em determinadas áreas, salientando os temas que mais foram citados, também contribuindo com a inovação cientifica.

Visando uma análise das temáticas que estão sendo mais abordadas na área da geografia econômica, este trabalho tem como objetivo apresentar uma análise interpretativa dos trabalhos publicados nos anais do XI Encontro Nacional da Associação Nacional de Pósgraduação e Pesquisa em Geografia (ENANPEGE), realizado na cidade de Presidente Prudente (SP), no período de 09 a 12 de outubro de 2015. Os trabalhos encontram-se em dois grupos de Trabalhos (GTs):

"Desenvolvimento Regional e Infraestrutura" - com a publicação de 35 trabalhos completos;

8 "Formações Socioespaciais: progresso técnico no espaço urbano e agrário" - com a publicação de 22 trabalhos completos.

9 O Grupo de Trabalho intitulado "Desenvolvimento Regional e Infraestrutura" aborda uma temática essencial diante das características atuais do processo de desenvolvimento brasileiro, o qual é marcado pelo fortalecimento da intervenção do Estado; retomada da elaboração de políticas públicas e dos investimentos em infraestruturas; novos modelos regulatórios para a concessão dos serviços públicos; atuação das corporações e seu papel na internacionalização da produção. Este rupo de Trabalho tem origem na discussão acumulada pelo Grupo de Estudos em Desenvolvimento Regional e Infraestruturas (GEDRI), do Grupo de Estudos da Dinâmica Econômica, e do Núcleo de Pesquisa Espaço e Economia (NuPEE).

10 O GT proposto tem o objetivo de aglutinar 5 eixos de pesquisa: 1) Circulação, transportes e logística; 2) Financeirização do território nacional; 3) Políticas públicas e desenvolvimento regional; 4) Desenvolvimento econômico, política industrial e comércio exterior; 5) Agronegócio e circuitos espaciais da produção. Tem-se como meta a criação de espaços de discussão que permita a socialização das experiências de pesquisa, reunião de um acervo qualificado com desdobramentos para a qualificação da pós-graduação e efetiva contribuição ao debate nacional.

O GT "Formações Socioespaciais: progresso técnico no espaço urbano e agrário" constata que a crise da economia mundial, iniciada em 1973, trouxe para o debate acadêmico as questões referentes à inovação tecnológica como possibilidade de retomada do crescimento econômico. Contudo, a formação socioespacial estado-unidense com sua política de liberalização do comércio internacional, oligopolização da economia, financeirização e políticas neoliberais, sobretudo, para fora, retardou o processo de destruição criativa e impôs diferentes estratégias às variadas formações socioespaciais do centro e da periferia do sistema capitalista. Assim sendo, esse GT, objetiva discutir o impacto dessas políticas e do progresso técnico no desenvolvimento econômico mundial/ nacional/regional/local. Este não está dividido em eixos.

A presente pesquisa tem como intuito principal Realizar uma reflexão sobre as pesquisas de geografia econômica, que foram desenvolvidas na pós-graduação da Geografia 
nacional, entre os anos de 2014-15, utilizando dos seguintes fundamentos: Leitura e análise qualitativa e quantitativa dos 57 trabalhos apresentados no ENANPEGE de 2015, realização de leitura do referencial teórico, e construção de um quadro síntese sobre os trabalhos.

\section{Análise dos trabalhos de geografia econômica}

12 A seguir as informações sobre os trabalhos estão sintetizadas em dois quadros. 0 quadro 1 contém as informações dos 35 trabalhos do GT (1) "Desenvolvimento Regional e Infraestrutura”, e o quadro 2 dos 22 trabalhos do GT (2) “Formações Socioespaciais: progresso técnico no espaço urbano e agrário".

Quadro 1. Síntese dos trabalhos apresentados no Grupo de Trabalho "Desenvolvimento Regional e Infraestrutura" do XI Encontro Nacional da ANPEGE - Presidente Prudente - 2015.

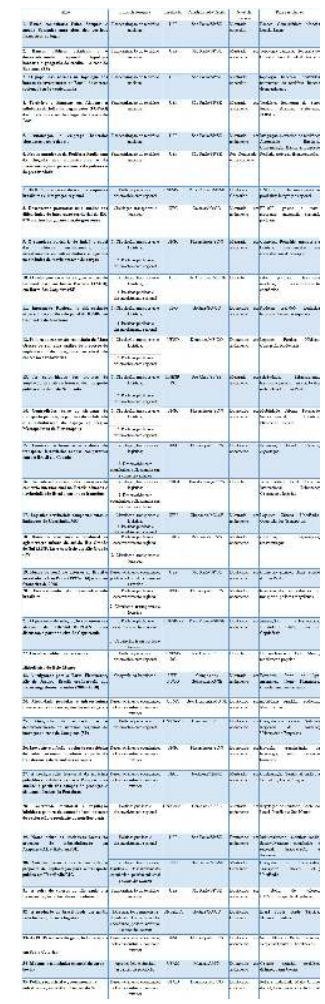

Fonte: Anais do XI Encontro Nacional da ANPEGE, 2015. Org.: Os autores. 
Quadro 2. Síntese dos trabalhos apresentados no Grupo de Trabalho " Formações Socioespaciais: progresso técnico no espaço urbano e agrário" do XI Encontro Nacional da ANPEGE - Presidente Prudente -2015.

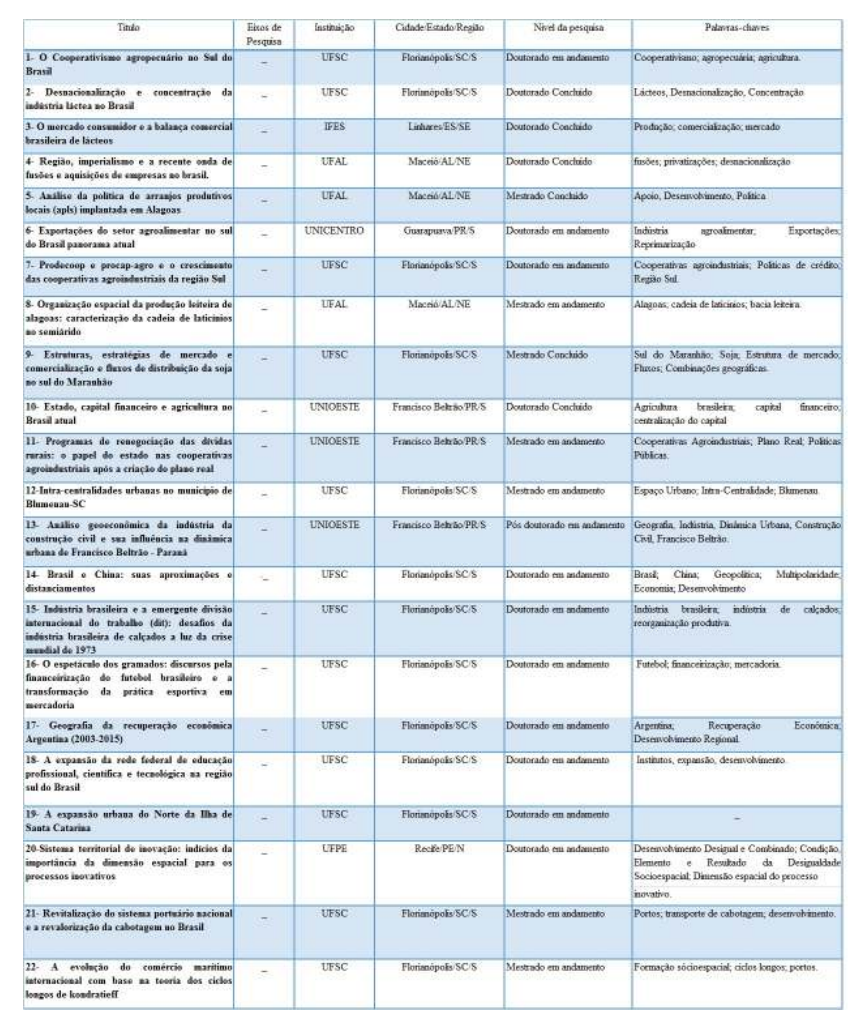

Analisando o quadro 1 observa-se que a região que mais apresentou trabalhos é a região Sudeste (19), em seguida a região Sul (8), Centro-Oeste (5), Nordeste (2) e o Norte (1).

Em relação ao nível das pesquisas, no GT 1 temos:
Dessa forma analisamos que os nivveis de pesquisa que possuem maior representação no GT são: Doutorado em andamento com 37,14\%, e mestrado em andamento com 34,28\% representando $71,42 \%$ dos 35 trabalhos. número de pesquisas são:

Universidade de São Paulo: 9

Universidade Federal de Santa Catarina: 6

Universidade Federal da Grande Dourados: 2

Universidade Estadual Paulista em Rio Claro: 2

Universidade Federal de Uberlândia: 2

Universidade Federal de Goiás: 2 
O restante das Universidades teve apenas uma publicação cada (visualizar no quadro 1, coluna-instituição).

No eixo intitulado de Financerização do território Nacional encontram-se 8 trabalhos. Os principais assuntos abordados foram: o sistema financeiro e bancário nacionais, topologia bancária; relacionado com suas influências sobre os territórios, regiões e a sociedade brasileiros. Logo resolvemos destacar as seguintes informações.

Os bancos são instituições que atuam levando recursos das áreas do interior do estado em direção a capital;

A distribuição dos agentes relacionados aos mercados financeiros se dá em sua maior parte em poucas cidades, sendo a maioria na região concentrada ${ }^{1}$. Com destaque para a cidade de São Paulo, a qual detém o maior número de corretoras. Visto que a localização das sedes empresariais nas metrópoles é de extrema importância devido à proximidade com os principais centros empresariais;

4 Constatou-se algumas mudanças na topologia bancária, como: a expansão e estabilização do número de agências bancárias no interior dos estados; o aumento do número de agências na região metropolitana e; o processo de diversificação/especialização das funcionalidades de alguns desses fixos (como por exemplo, os correspondentes bancários). (GUERIM, 2015);

5 Os bancos se tornaram relevantes agentes na execução de parte das atividades públicas, especialmente dos municípios, uma fonte para angariar recursos financeiros através da administração da $\mathrm{FOPAG}^{2}$ de servidores, fornecedores, arrecadação de tributos etc. (SANTOS, 2015);

36 No ano de 2000 farmácias, padarias, lotéricas, supermercados etc. passaram a oferecer serviços bancários. Além disso, a partir de então ocorreu um aumento no número de contas correntes com internet banking, a qual atingiu 49 milhões em 2011. Da mesma forma, se evidenciam as contas acessadas vias celulares smartphones (mobile banking) que passou de zero em 2008 para 3,3 milhões em 2011. (IAMONTI, 2015).

De acordo com a Federação Brasileira de Bancos (FEBRABAN), em 2016 Mobile banking e Internet Banking já representavam mais da metade das transações bancárias, respectivamente com 18,6 bilhões (27\%) e 15,5 bilhões (24\%) contra 5,6 bilhões (9\%) das agências - constituindo-se nas principais modalidades;

Em São Paulo a ascensão da financeirização levou a população de alguns bairros periféricos ao endividamento. $O$ crédito pessoal tornou-se uma das formas mais fáceis de acesso ao dinheiro pela população de baixa renda;

Em referência aos demais eixos (Circulação, transportes e logística; Políticas públicas e desenvolvimento regional; e, Desenvolvimento econômico, política industrial e comércio exterior) estes foram analisados em conjunto, pois a maioria dos trabalhos apresentavam simultaneamente dois eixos. Os estudos salientam que:

40 As exportações destinadas ao Mercosul representam 11\% das exportações nacionais e estas seguem majoritariamente pelo modal rodoviário. Da mesma forma que a carga nacional, a qual é dependente do transporte rodoviário, o modal é responsável pela movimentação de cerca de $58 \%$ das cargas, e $95 \%$ dos passageiros no País.

O período rodoviarista dos transportes públicos surgiu quando os trilhos tornaram-se caros. Hoje no Brasil o Governo Federal busca realizar a expansão da malha e a construção 
de grandes eixos ferroviários, através de uma maior participação do setor privado, uma vez que parte considerável dos investimentos é proveniente dos recursos públicos. A preocupação por essa expansão se da devido ao fato de que o sistema ferroviário é o que transporta maior volume e peso de cargas. Hoje este modal é responsável por apenas $25 \%$ do transporte de cargas, mesmo sendo mais vantajoso.

42 A escolha entre o sistema sobre trilhos e o sistema sobre pneus referente ao transporte de pessoas decorre da escolha política, a qual está relacionada com a lucratividade de empreendimentos. Trens suburbanos e regionais, metrôs e VLT's ${ }^{4}$ necessitam de investimentos de grande porte e refletem na valorização imobiliária de seus entornos. Já os corredores de ônibus não demandam grandes investimentos, e estão dispostos principalmente em áreas das cidades que ainda buscam valorização imobiliária (SALOMÃO, 2015). Houve o estudo para a implantação do VLT em Uberlândia (MG), prevista para os próximos 10 anos (BERNARDES; FERREIRA, 2015);

43 A BR-070, que seu tem início em Brasília e término em Cáceres no Mato Grosso, apresentou realidades diferentes no seu decorrer, por se tratar de uma via de circulação tida como radial de integração da capital federal ao extremo do país. Em alguns trechos, apontou caminhos desconexos, que atrasam o transporte e as trocas do comércio. Por outro lado, na mesma rodovia, em trechos diferentes, geralmente em relevos mais planos, a paisagem apresenta pista duplicada, iluminação e cidades modernizadas pela economia da soja. A modernização não foi concluída em alguns trechos desta rodovia por apresentar um traçado que não interessa na sua totalidade aos setores produtivos hegemônicos da região e do país (MARITIS, 2015);

o Conselho Sul-Americano de Infraestrutura e Planejamento (Cosiplan) tem como objetivo promover a integração econômica e física na América do Sul através da modernização da infraestrutura de transportes, a fim de promover maior articulação entre os mercados (além dos transportes, visa, ainda, as infraestruturas de energia e telecomunicações). Uma das iniciativas do projeto é o Corredor ferroviário bioceânico Paranaguá-Antofagasta, que propõe a construção de um corredor ferroviário para acesso aos oceanos Atlântico e Pacífico, com o objetivo de facilitar o transporte de cargas (D. CRUZ, 2015);

Abrindo um parêntese, (OLIVEIRA, 2011) aponta que a definição do traçado prioritário para a conexão ferroviária bioceânica de nada adiantará se não for acompanhada de estímulos pelos respectivos Estados nacionais para que sejam incrementadas atividades intensivas em tecnologia e conhecimento no entorno das estações ferroviárias. A referida conexão tende a estimular atividades primarias, porém, a conexão ferroviária pode vir a ser apropriada tanto pelos interesses primário-exportadores como por aqueles que giram em torno da industrialização e da agregação de valor produtivo. 0 mesmo alerta que os gastos com o empreendimento só se justificam caso sejam acompanhados de outras medidas que estimulem a agregação de valor produtivo.

46 As atividades petrolíferas ocasionam grandes impactos econômicos, e mudanças na organização territorial, transformações essas que no Brasil decorrem das atividades da Petrobras;

Verifica-se a falta de maiores investimentos nos portos do país, os quais apresentam necessidade de modernização, para que consigam atender as demandas existentes;

Os portos secos no Brasil foram criados a partir de 1970, como Centrais Aduaneiras do Interior. Um dos portos secos que merece destaque é o de Foz do Iguaçu (PR), o qual 
configura-se com um nodo estratégico na circulação de mercadorias e serviços, e este movimentou R $\$ 11$ bilhões em mercadorias, de janeiro a setembro de 2014, com um fluxo de 120.125 veículos (JUNIOR, 2015);

De acordo com o Plano Nacional de Logística e Transportes (MT, 2007, p.71) "essa conformação da matriz de transportes brasileira se traduz em desvantagens comparativas em termos de competitividade internacional de seus produtos de exportação, na medida em que eleva os custos de transporte e impacta negativamente os custos logísticos totais". Analisando o Quadro 2, constata-se que no GT "Formações Socioespaciais: progresso técnico no espaço urbano e agrário" a maioria dos trabalhos apresentados são da região Sul (17), seguido pela região Nordeste (4), e sudeste (1). Diferentemente do GT 1, o qual teve a maioria dos trabalhos provenientes de instituições do Sudeste.

O nível de pesquisa do GT ocorre da seguinte maneira:

Mestrado Concluído: 2

Mestrado em andamento: 5

Doutorado Concluído: 4

Doutorado em andamento: 10

Pós-doutorado em andamento: 1

2 os níveis de pesquisa que mais se destacam são os de doutorado em andamento com $45,45 \%$ e em seguida o mestrado em andamento com $22,72 \%$ representando $68,18 \%$ dos trabalhos.

As Universidades representadas no GT (com 2 ou mais estudos) por ordem decrescente do número de pesquisas são:

ante das Universidades teve apenas uma publicação cada (visualizar o quadro 2). Este GT não está dividido em eixos, portanto sua análise ocorreu de uma forma conjunta. Dentre os assuntos que mais foram ressaltados podemos citar: cooperativismo, politicas publicas, inserção de capital estrangeiro no Brasil. Os estudos destacam:

Aumento no número de Universidades e campis, tanto publicas como privadas, em todas as regiões, as quais foram criadas com o objetivo de reduzir as desigualdades no seu entorno. Os campis universitários são de extrema importância na formação do espaço, visto que ao redor destes ocorre um incremento do comércio local, o aquecimento do mercado de imóveis, o aumento da arrecadação municipal e a geração de novos empreendimentos.

A China é um dos principais parceiros comerciais do Brasil, e é extremamente competitiva em vários setores tradicionais de exportação brasileira, como têxteis, calçados e manufaturas simples. Portanto mesmo que esta represente um potencial parceiroestratégico o Brasil necessita "diversificar-se", cuidando de seus interesses nacionais e não se apoiar somente no capital Chinês (PRESTES, 2015);

Nota-se que a partir da década de 1990, houve um processo maior de inserção de capital estrangeiro na economia do Brasil, momento este em que muitas empresas nacionais 
foram incorporadas, principalmente no setor de autopeças e eletrodomésticos: Metal Leve, Arno, Cofap, Iochpe-Maxion, Lacta (CORRÊA, 2015);

Esse processo de desnacionalização também atingiu a indústria láctea, a qual passou por processos de fusões e aquisições. Dentre as 12 maiores empresas de lácteos atuantes no Brasil 5 são multinacionais captando aproximadamente $25 \%$ do leite produzido (CAMILO, 2015);

67 Além dessas, as empresas de industrialização de alimentos, de carnes, de produção de insumos agrícolas, entre outras, também sofreram processos de fusões e aquisições. Os grupos internacionais adquiriram empresas para eliminar concorrentes e absorver seu conhecimento produtivo e dos mercados específicos. Entre os anos de 1994 e 2003 foram registrados 312 processos de fusões e aquisições nos setores nacionais de alimentos, bebidas e fumo (MEDEIROS, 2015);

Abrindo um parêntese (SCHERER, 2004, p.108) afirma que:

O investimento direto estrangeiro passou a ser visto como aquele elemento capaz de dinamizar a economia brasileira em um ambiente de redução da capacidade de investimento estatal, tendo como vantagens o acesso à tecnologia de ponta, ao financiamento externo e aos canais de comercialização externos.

Esse aumento/retomada na inserção de capital estrangeiro no Brasil foi uma das consequências do Plano Real ${ }^{5}$. Porém todos esses objetivos pretendidos não foram alcançados.

70 A junção entre políticas do Estado e produtores fez com que o cooperativismo agropecuário do Sul do Brasil passasse a participar de forma ativa na economia nacional. Visto que o mesmo fez parte do plano nacional de substituição das importações a fim de criar capacidade de produção de alimentos e matérias primas, ambas indispensáveis para dar sequência ao projeto de industrialização brasileira. Os principais destinos dos produtos das cooperativas agropecuárias brasileiras são países consumidores como os Estados Unidos, China e Alemanha, Emirados Árabes e Japão. (FARIAS, 2015)

71 Os programas PRODECOOP ${ }^{6}$ e PROCAP-AGRO $^{7}$ proporcionaram um novo ciclo de crescimento do cooperativismo no pós-2000. A reestruturação do crédito permitiu que as cooperativas agropecuárias investissem em infraestrutura produtiva, comercial e na composição de capital de giro, elementos fundamentais para garantir o crescimento das empresas. A Região Sul concentrou a maior parte dos recursos (PADILHA, 2015);

72 Abrimos um parêntese para (GIMENES, 2007) a qual ressalta que: o cooperativismo se mostra de extrema importância para a economia brasileira, na medida em que atua apoiando o desenvolvimento econômico e social, principalmente das pequenas propriedades rurais. Propiciou ao agronegócio o desenvolvimento principalmente nas décadas de 1960 e 70, devido à organização das cadeias produtivas, a difusão da tecnologia e a viabilização da infraestrutura. De acordo com a organização das cooperativas brasileiras (OCB, 2013, p. 19), o Sudeste é a região que mais apresenta cooperativas (2.357) e cooperados (5,1 milhões), seguida pela região Sul com (1011) cooperativas e $(4,4$ milhões) de cooperados;

73 A região Sul do Brasil apresenta uma estrutura produtiva, contemplada por grandes grupos agroindustriais, ligados principalmente ao complexo da soja e da carne e que atuam, sobretudo, no processamento de gêneros agroalimentares. Os complexos da carne (US\$ 7.711 bilhões) e da soja (US\$ 11.666 bilhões) expressam uma ampla cadeia produtiva 
regional e são representados por grupos como BRF S/A, Bunge Alimentos S/A. e Cargill Agrícola (LACERDA, 2015);

O transporte e a armazenagem se apresentam como ponto de estrangulamento em algumas cidades, onde estradas intrafegáveis, sem asfalto, esburacadas são utilizadas para o transporte de cargas, fazendo com que o frete tenha um aumento no preço;

Ocorre uma especialização da produção, no que concerne a indústria calçadista brasileira. Franca (SP) e Novo Hamburgo (RS). No cenário internacional o Brasil alcançou o posto de um dos maiores produtores e exportadores mundiais de calçados, ficando na décima quinta posição em 2014, quando representamos 1,3\% do total comercializado no planeta (ROSA, 2015);

76 Transformação na estrutura urbana das cidades, através da desconcentração das atividades de serviços e comércio do centro, levando essas atividades econômicas para bairros mais afastados, criando dessa forma subcentros.

\section{Conclusões}

77 Verificamos que o Brasil um país com dimensões continentais apresenta desigualdades de investimento no setor de transportes. Ponto este que merece mais atenção por parte do Estado, visto que: "A rede de transportes é um conjunto interligado de rotas específicas ou não onde circulam pessoas, informações, capitais e mercadorias e ainda são capazes de protagonizar as ações de ordenamento e (re)ordenamento do território."(SILVA; RODRIGUES, 2015, p.8222). A circulação é essencial na qualidade do desenvolvimento social, político, ambiental e econômico da urbanização.

Portanto devido à importância desse setor, investir em fixos, reduzir os pontos de estrangulamento, diversificar a matriz de transportes, uma vez que o Brasil é dependente do modal rodoviário, são premissas necessárias para impulsionar o desenvolvimento do país, através da integração nacional; e dessa forma, também contribuindo para reduzir as disparidades regionais.

Em relação a outros aspectos apontados, houve a inserção de capital estrangeiro por meio das multinacionais a partir de 1990 no Brasil, o qual promoveu a desnacionalização da economia com fusões e aquisições de empresas brasileiras em diversos setores. E as cooperativas se mostraram muito importantes na economia do Brasil, agregando empresas que possuem interesses em comum, e assim conseguir vantagens econômicas.

Com referência às pesquisas notamos que em ambos os GT's a maior parte dos autores da são alunos que ainda estão com mestrado (17 trabalhos/29\%) e doutorado (23 trabalhos $/ 40,35 \%$ ) em andamento, mostrando que essa categoria é a que mais contribui para as pesquisas cientificas na pós-graduação. A maioria dos autores incluindo todos os níveis de pesquisa é proveniente de Universidades federais da região Sul, com destaque para a Universidade Federal de Santa Catarina (UFSC) que apresentou $19(33,33 \%)$ trabalhos no total de 57 .

81 Concluímos que através dessa pesquisa do estado da arte na geografia econômica foi possível verificar o que se produz contemporaneamente nessa subárea do conhecimento, contribuindo dessa forma com a produção/inovação cientifica. Essas informações coletadas também podem ser utilizadas como instrumento para solução de problemas. 


\section{BIBLIOGRAFIA}

ANPEGE. Anais do XI Encontro Nacional da ANPEGE. Presidente Prudente: UFGD Editora, 2015.

CAMILO, Pablo. J. Desnacionalização e concentração da indústria láctea no Brasil. Anais do XI

Encontro Nacional da ANPEGE. Presidente Prudente: UFGD Editora, 2015, p. 6130-6141.

CORRÊA, Domingos. Sávio. Região, imperialismo e a recente onda de fusões e aquisições de empresas no Brasil. Anais do XI Encontro Nacional da ANPEGE. Presidente Prudente: UFGD Editora, 2015, p. 6154-6165.

CRUZ, D. A. M. de O. O processo de integração Sul-americana através da IIRSA/COSIPLAN: uma discussão a partir do eixo de capricórnio. Anais do XI Encontro Nacional da ANPEGE.

Presidente Prudente: UFGD Editora, 2015, p. 8351-8362.

FARIAS, F. R. O cooperativismo agropecuário no sul do Brasil. Anais do XI Encontro Nacional da ANPEGE. Presidente Prudente: UFGD Editora, 2015, p. 6104-6128.

FEBRABAN (FEDERAÇÃO BRASILEIRA DE BANCOS). Inovação e Competição: Novos Caminhos para Redução dos Spreads Bancários ?. 2018.

FERREIRA, Norma Sandra de Almeida. As pesquisas denominadas "estado da arte". Educação \& Sociedade, Campinas, ano XXIII, no. 79, p. 257-272, 2002. Disponível em: http://www.scielo.br/ pdf/es/v23n79/10857.pdf< Acesso em: 23 de março de 2019.

FIRMINO, P. C. S. Notas sobre as iniciativas locais no processo de industrialização em Arapiraca/ AL e Itabaiana/SE. Anais do XI Encontro Nacional da ANPEGE. Presidente Prudente: UFGD Editora, 2015, p. 8195-8206.

GIMENES, R. M. T et al. Agronegócio cooperativo: a transição e os desafios da competitividade. Cadernos de Economia - Curso de Ciências Econômicas - Unochapecó, ano 11, n. 20, p. 45-72, jan./jun. 2007.

GUERIM, T.G.M. BANCOS PÚBLICOS ESTADUAIS E O DESENVOLVIMENTO REGIONAL: Topologia Bancária e Geografia do Crédito - O caso do Banestes (ES). Anais do XI Encontro Nacional da ANPEGE. Presidente Prudente: UFGD Editora, 2015, p.8433-8446.

IAMONTI, V. Z. Automação e emprego bancário no Brasil: elementos para o debate. Anais do XI Encontro Nacional da ANPEGE. Presidente Prudente: UFGD Editora, 2015, p. 8566-8576.

ISOPPO, K. K. V. Inovação e difusão: evolução tecnológica do setor cerâmico brasileiro a partir da transferência de tecnologia europeia. Anais do XI Encontro Nacional da ANPEGE. Presidente Prudente: UFGD Editora, 2015, p. 8315-8326.

JESUS, G. V. de. A expansão urbana do Norte da Ilha de Santa Catarina. Anais do XI Encontro Nacional da ANPEGE. Presidente Prudente: UFGD Editora, 2015, p. 6303-6315.

JUNIOR, R. F. D.S. Controle e tributação das operações de comércio internacional no Brasil: aduanas e territorialidade fiscal a partir das fronteiras. Anais do XI Encontro Nacional da ANPEGE. Presidente Prudente: UFGD Editora, 2015, p. 8339-8350.

LACERDA, A. C. Exportações do setor agroalimentar no sul do Brasil panorama atual. Anais do XI Encontro Nacional da ANPEGE. Presidente Prudente: UFGD Editora, 2015, p. 6176-6186. 
MARITIS, M. Desconexão portuária: uma análise das dificuldades de integração territorial da BR-070 nos trechos goiano e mato-grossense. Anais do XI Encontro Nacional da ANPEGE. Presidente Prudente: UFGD Editora, 2015, p. 8530-8541.

MEDEIROS, Marlon C. Estado, capital financeiro e agricultura no Brasil atual. Anais do XI Encontro Nacional da ANPEGE. Presidente Prudente: UFGD Editora, 2015, p. 6223-6232.

OCB (Organização das Cooperativas Brasileiras). Relatório de atividades 2004. OCB: Brasília, 2013.

OLIVEIRA, M. G. de. A Ferrovia Bioceânica Paranaguá Antofagasta e a controvérsia entre o modelo primário-exportador e o modelo desenvolvimentista. Oikos, Rio de Janeiro, volume 10, n. 2, p. 243-266, 2011.

PADILHA, W. Prodecoop e procap-agro e o crescimento das cooperativas agroindustriais da região sul. Anais do XI Encontro Nacional da ANPEGE. Presidente Prudente: UFGD Editora, 2015, p. 6188-6198.

MT (MINISTÉRIO DE TRANSPORTES); MD MINISTÉRIO DA DEFESA). Plano nacional de logística e transportes. Relatório executivo. Brasília: MT/MD, 2007.

ROSA, H. R. da. Indústria brasileira e a emergente divisão internacional do trabalho (DIT): desafios da indústria brasileira de calçados a luz da crise mundial de 1973. Anais do XI Encontro Nacional da ANPEGE. Presidente Prudente: UFGD Editora, 2015, p. 6282-6293.

SALOMÃO, V. As seletividades dos projetos de ampliação das infraestruturas de transporte público no estado de São Paulo. Anais do XI Encontro Nacional da ANPEGE. Presidente Prudente: UFGD Editora, 2015, p. 8375-8385.

SANTOS, F. B. Território e finanças em Alagoas: a influência da folha de pagamentos (FOPAG) das prefeituras na topologia do banco do Brasil. Anais do XI Encontro Nacional da ANPEGE. Presidente Prudente: UFGD Editora, 2015, p. 8363-8374.

SCHERER, A. L. F. Investimento direto estrangeiro, fusões e aquisições e desnacionalização... Investimento direto estrangeiro, fusões e aquisições e desnacionalização da economia brasileira: um balanço da década do Plano Real. Indicadores Econômicos FEE, Porto Alegre, v. 32, n. 2, p. 107-128, ago. 2004.

SILVA, F. de. O; RODRIGUES, W. F. LOGÍSTICA TERRITORIAL: COMPORTAMENTOS E LIMITAÇÕES DE UBERLÂNDIA/MG. Anais do XI Encontro Nacional da ANPEGE. Presidente Prudente: UFGD Editora, 2015, p. 8219-8230.

SOARES, M. Alfabetização no Brasil - O Estado do conhecimento. Brasília: INEP/MEC, 1989.

\section{NOTAS}

1. Formada pelas regiões Sudeste e Sul. Conceito formulado pelo geógrafo Milton Santos.

2. Folha de pagamento.

3. Os $40 \%$ restantes estão distribuídos em outras modalidades (correspondentes, contact centers, POS, Terminais de auto atendimento).

4. Veículo Leve sobre trilhos

5. O Plano Real foi um processo de estabilização econômica iniciado em 1993 no governo de Itamar Franco (1992-94). Seu sucesso representou a quebra da espinha dorsal da inflação no Brasil. A entrada em circulação do real em 1ํo de julho de 1994 mudou o cenário de uma inflação que, no acumulado em doze meses, chegou a $4.922 \%$ em junho de 1994, às vésperas do 
lançamento da nova moeda. Apesar da estabilização econômica, ele resultou na ampliação da concentração de renda no Brasil.

6. Programa de desenvolvimento cooperativo para á agregação de valor a produção agropecuária

7. Programa de Capitalização das Cooperativas de Produção Agropecuária

\section{RESUMOS}

O presente trabalho teve como intuito realizar uma pesquisa do estado da arte, a qual é baseada em uma análise interpretativa dos trabalhos publicados nos anais do XI Encontro Nacional da Associação Nacional de Pós-graduação e Pesquisa em Geografia (ENANPEGE), realizado na cidade de Presidente Prudente (SP), no período de 09 a 12 de outubro de 2015. Os trabalhos encontramse em dois grupos de Trabalhos (GTs): "Desenvolvimento Regional e Infraestrutura" -com a publicação de 35 trabalhos completos, e "Formações Socioespaciais: progresso técnico no espaço urbano e agrário" - com a publicação de 22 trabalhos completos. Através da analise destes é possível ter uma visão sobre os temas mais representados na área da geografia econômica, contribuindo dessa forma com a evolução cientifica.

Le présent travail visait à mener une recherche sur l'état de la technique, qui repose sur une analyse interprétative des travaux publiés dans les annales de la XI e Réunion nationale de l'ENANPEGE (Association nationale des hautes écoles et de la recherche en géographie), tenue à Du 9 au 12 octobre 2015, les documents sont répartis dans deux groupes de travail: "Développement régional et infrastructure", avec la publication de 35 documents complets et "Formations socio-spatiales". : progrès technique dans l'espace urbain et agraire "- avec la publication de 22 articles complets. Grâce à l'analyse de ceux-ci, il est possible d'avoir une vue d'ensemble des thèmes les plus représentés dans le domaine de la géographie économique, contribuant ainsi à l'évolution scientifique.

El presente trabajo tuvo como objetivo realizar una investigación del estado del arte, la cual se basa en un análisis interpretativo de los trabajos publicados en los anales del XI Encuentro Nacional de la Asociación Nacional de Postgrado e Investigación en Geografía (ENANPEGE) en el período de 09 a 12 de octubre de 2015. Los trabajos se encuentran en dos grupos de Trabajos (GTs): "Desarrollo Regional e Infraestructura" - con la publicación de 35 trabajos completos, y " Formaciones Socioespaciales: progreso técnico en el espacio urbano y agrario "- con la publicación de 22 trabajos completos. A través del análisis de estos es posible tener una visión sobre los temas más representado en el área de la geografía económica, contribuyendo de esa forma con la evolución científica.

The present work aimed to carry out a state - of - the - art research based on an interpretative analysis of the works published in the annals of the XI National Meeting of the National Association of Graduate Studies and Research in Geography (ENANPEGE) in the city of Presidente Prudente (State of São Paulo), from October 9 to 12, 2015. The work is divided into two Working Groups (WGs): "Regional Development and Infrastructure" - with the publication of 35 complete papers, Socio-spatial formations: technical progress in urban and agrarian space "- with the publication of 22 complete papers. With through the analysis of these it is possible to have an overview of the most represented themes in the area of economic geography, thus contributing to the scientific evolution. 
ÍNDICE

Mots-clés: Production académique, état de l'art, géoéconomie, Enanpege 2015.

Palavras-chave: Produção acadêmica, estado da arte, geoeconomia, Enanpege 2015.

Palabras claves: Producción académica, estado del arte, geoeconomia, Enanpege 2015.

Keywords: Academic production, state of art, geoeconomics, Enanpege 2015.

\section{AUTOR}

\section{LUANA GUIDONI}

Graduanda em Licenciatura em Geografia pela UNICENTRO (PR). Bolsista Voluntária de Iniciação Científica - área: Geografia Econômica. Bolsista do Programa de Residência Pedagógica (CAPES). E-mail: luanaguidoni@gmail.com 